\title{
ARI JANTSCH: TRAJETÓRIA DE UM PEQUENO (AINDA) AGRICULTOR A PROFESSOR UNIVERSITARIO E REFLEXÕES PARA A EDUCAÇÃO DO CAMPO
}

\author{
ARI PAULO JANTSCH: THE STORY OF A SMALL (AN STILL) FARMER THAT \\ BECAME A UNIVERSITY PROFESSOR AND REFLECTIONS FOR RURAL EDUCATION \\ ARI PAULO JANTSCH: SU TRAYECTORIA DE PEQUEÑO (AÚN) AGRICULTOR A
PROFESOR UNIVERSITARIO Y REFLEXIONES PARA LA EDUCACIÓN RURAL
}

Natacha Eugenia Janata* natacha.janata@ufsc.br

\begin{abstract}
REVISTA PEDAGÓGICA
Revista do Programa de Pós-graduação em Educação da Unochapecó | ISSN 1984-1566

Universidade Comunitária da Região de Chapecó | Chapecó-SC, Brasil

Como referenciar este artigo: JANATA, N. E. Ari Jantsch: trajetória de um pequeno (ainda) agricultor a professor universitário e reflexões para a educação do campo. Revista Pedagógica, Chapecó, v. 17, n. 36, p. 69-81, set./dez. 2015.
\end{abstract}

RESUMO: A finalidade deste texto é apresentar uma sistematização biográfica de Ari Paulo Janstch (in memorian), professor da UFSC no período de 1991 a 2010, atuando na área de filosofia da educação na graduação, bem como na linha de pesquisa Trabalho e Educação no Programa de Pós-graduação em Educação da instituição, entre outras atividades. Um levantamento das produções deu início à pesquisa bibliográfica, complementada com a realização de cinco entrevistas, buscando amplitude de situações nas inter-relações pessoais e profissionais. Com a limitação de tempo e espaço para a escrita, também critério definidor, constituiu-se um grupo de cinco depoentes, entre orientador, orientado, professores da UFSC e aluna na pós-graduação. A síntese evidencia conceitos que caracterizam sua vida e produção intelectual: conhecimento e interdisciplinaridade. Para concluir, a partir do escopo da minha atuação no ensino, pesquisa e extensão, sistematizo uma breve reflexão sobre as contribuições do pensamento de Ari para o debate teórico-prático da Educação do Campo.

Palavras-chave: Biografia. Conhecimento. Interdisciplinaridade. Educação do campo.

ABSTRACT: The purpose of this paper is to present a biographical systematization of Ari Paulo Janstch (in memoriam), a UFSC professor between the period of 1991-2010, working in the field of education philosophy for undergraduated students as well as in the Work and Education research line in the Graduate Education Program in the institution, among other activities. A survey of productions began the literature, complemented with the development of five interviews, searching range of situations in personal and professional interrelationships. With the limitation of time and space for writing, it constitutes a group of five interviewees, between guiding oriented, UFSC teachers and student in posgraduate school. The summary highlights some of the key concepts that characterize his life and intellectual output. Finally, from the scope of my work in teaching, research and post graduation, a systematized reflection on the contributions of the thought of Ari to the theoretical and practical discussion of Rural Education.

Keywords: Biography. Knowledge. Interdisciplinarity. Rural education.

RESUMEN: El propósito de este trabajo es presentar una sistematización biográfica de Ari Paulo Janstch (in memoriam), profesor de la Universidad Federal de Santa Catarina - UFSC en el período de 1991 a 2010, el cual se desempeñó entre otras actividades, en el área de filosofía de la educación a nivel de pregrado, así como en la línea de Investigación, Trabajo y Educación, perteneciente al Programa de posgrado en Educación de la misma institución. Una exploración de su producción académica dio inicio a la revisión bibliográfica, que se complementa con la realización de varias entrevistas, buscando variedad de situaciones en las interrelaciones personales y profesionales. A partir del tiempo disponible, fue conformado un grupo de cinco entrevistados, entre orientador, orientado, profesores de la Universidad y una estudiante de posgrado. Este documento describe algunos de los conceptos centrales que caracterizan su vida y su producción intelectual. Finalmente, a partir del enfoque de mi trabajo en educación, investigación y extensión, sistematizo una reflexión sobre las contribuciones del pensamiento de Ari Paulo Jantsch para el debate teóricopráctico de la educación rural.

Palabras clave: Biografía. Conocimiento. Interdisciplinariedad. Educación Rural. 


\begin{abstract}
* Doutora em Educação/CED/UFSC. Coordenadora do Grupo de Pesquisa Ensino e Formação de Educadores em Santa Catarina (GPEFESC). Realiza pesquisas com as problemáticas da "Juventude e Educação do Campo". Integrante da pesquisa: "Programa Apoyo al Sector Educativo del Mercosur (PASEM). Red Universidad Nacional de Córdoba (UNC)". Projeto: "Estudio de la situación de las políticas de formación docente para educación de jóvenes y adultos y educación rural en países del Mercosur”.
\end{abstract}

${ }^{1}$ Deixo aqui registrado meu sincero e profundo agradecimento à professora Dercy Akele, que com suas palavras de acolhimento e encorajamento, fizeram desse desafio algo bom e prazeroso de ser desfrutado!

${ }^{2}$ Minha opção foi fazer uso do seu primeiro nome, uma vez que essa era a forma corriqueira com que seus alunos, colegas e amigos o chamavam.

${ }^{3}$ Por indicação da professora Valeska Nahas Guimarães, fiz contato com Leila Procópia do Nascimento, coorientada pelo Ari, tendo defendido sua dissertação junto ao PPGE-UFSC em 2007, entretanto não foi possível a ela, devido ao tempo, responder às questões.

\footnotetext{
${ }^{4}$ A indicação de cada entrevistado foi feita a priori com a colaboração do Prof. Lucídio Bianchetti, sendo que a caracterização apresentada, por sua vez, é produto das próprios depoimentos.
}

\section{INTRODUÇÃO}

Assumi o desafio ${ }^{1}$ de trazer à tona as contribuições do professor Ari Paulo Jantsch (in memorian) para o pensamento educacional do sul brasileiro e, quiçá, de todo o país. Um relato da sua breve vida inicia o artigo. De antemão fica explícito que a abordagem biográfica se deu no plano mais restrito de sua produção acadêmico-científica, fazendo entrecruzamentos com questões de ordem pessoal quando essa relação se mostrou pertinente para demonstrar a importância e contundência de suas elaborações. Na sequência do texto, apresento uma síntese de alguns conceitos trabalhados por $\mathrm{Ari}^{2}$, para então destacar as possíveis contribuições desde um foco ao qual estou vinculada pessoal, política e cientificamente: a Educação do Campo.

O percurso metodológico para a sistematização envolveu um levantamento bibliográfico do material, sobretudo dos livros publicados por Ari. Paralela e complementarmente recolhi depoimentos ${ }^{3}$ dos seguintes professores, colegas, amigos e ex-orientandos (categoria na qual me incluo): Valdemar Sguissardi, amigo e orientador do doutorado, entrevistado por videoconferência, em 19/11/2015; Lucídio Bianchetti, amigo, também professor da UFSC, com o qual Ari compartilhou sua produção intelectual e de vida, entrevistado presencialmente, em 01/12/2015; Valeska Nahas Guimarães, professora da UFSC, da mesma linha de pesquisa na Pós-graduação em Educação (PPGE), que possuía uma amizade-irmã com Ari, o qual a chamava por "mana", entrevistada presencialmente, em 03/12/2015; Leyli Abdala Pires Boemer, aluna durante o Mestrado em Educação, tendo cursado três disciplinas ofertadas pelo Ari no PPGE, também filósofa de formação, servidora da UFSC, entrevistada presencialmente, em 03/12/2015 e Rafael Rodrigo Muller, seu coorientado no mestrado e orientado no doutorado no PPGE da UFSC, também amigo, com depoimento feito por meio de perguntas enviadas pelo correio eletrônico e devolvidas em 12/12/2015. ${ }^{4}$

Os critérios para definição desse grupo consideraram o exíguo tempo para a escrita do texto, bem como a busca por uma amplitude de situações nas inter-relações pessoais e profissionais entre os entrevistados e Ari. Para fins de sistematização a opção foi evidenciar elementos teóricos que reaparecem ao longo de sua trajetória, os quais oferecem chaves de análise para a curta reflexão final, relacionada com a Educação do Campo.

Ao fazer a leitura do material bibliográfico fui percebendo que Ari tinha o hábito de destacar os conceitos centrais em todos os seus textos, deixando-os em negrito. Outra característica nitidamente marcante são as suas explicações, seja pelas caixas de textos apensadas na escrita - denominadas em sua tese por "Box", ou ainda pela separação em parênteses e/ou com travessões entre as frases. Essa constatação foi reafirmada nas entrevistas com Valdemar Sguissardi (em 19/11/2015) e também com Lucídio 


\footnotetext{
${ }^{5}$ A publicação de 2001 foi originalmente apresentada como tese de doutorado, defendida no ano 1997 na Universidade Metodista de Piracicaba, sob orientação do professor Dr. Valdemar Sguissardi. O título do livro é similar ao da tese: "Pequeno (ainda) agricultor e racionalidade educativa".

${ }^{6} \mathrm{O}$ texto foi apresentado primeiramente em Sessão Especial da $32^{\text {a }}$ Reunião Anual da Associação Nacional de Pós-graduação e Pesquisa em Educação, no dia 07/10/2009, organizada pelos Grupos de Trabalho de Política de Educação Superior (GT 11) e Filosofia da Educação (GT 17). Posteriormente, com alguns acréscimos, o texto foi publicado (cf. JANSTCH, 2010).
}

Bianchetti (em 01/12/2015), para os quais essa era uma postura filosófica assumida por ele, com sua busca por se fazer compreender o mais amplamente possível. Assim, minha escolha foi por marcar em negrito os conceitos centrais trabalhados por Ari eleitos para essa sistematização e finalizar o artigo com um Box que apresenta por itens uma biografia resumida.

Ainda como introdução, ressalto mais um atributo seu: a abertura ao diálogo crítico, combatendo o pensamento "moralizado e polarizado", os quais, para Ari, assumem um "caráter acientífico". O seguinte trecho de Engels, ilustrativo dessa afirmação, perpassa sua trajetória intelectual, indo desde suas iniciais elaborações (JANTSCH; BIACNHETTI, 1995), estando presente em sua tese de doutorado (JANSTCH, 20015 ${ }^{5}$ ) e, por fim, em seu último texto publicado ${ }^{6}$.

Segundo Engels: a) ‘A verdade e o erro, como todos os conceitos que se movem dentro de análises polares, só têm aplicação absoluta dentro de uma zona muito limitada, [...] como o próprio Sr. Dühring saberia ver se tivesse uma noção dos primeiros rudimentos da dialética, que são justamente os que tratam da limitação de todas as análises polares. Tão logo a análise de verdade-erro se afasta daquela zona circunscrita em que se deve mover, ela se converte de absoluta em relativa e perde, assim, todo e qualquer valor, como meio estritamente científico de expressão'. b) 'Se nada ganhamos com os conceitos de verdade e erro, menos ainda alcançamos com os de bem e de mal. Essa antítese move-se, pura e exclusivamente, dentro da órbita moral, isto é, num terreno que pertence à história humana, onde já sabemos que pouquíssimas verdades definitivas e inapeláveis podem fecundar' (ENGELS, 1979 apud JANSTCH, 1995; 2001; 2010).

A postura dialógico-crítica, contrária à polarização e à moralização do pensamento, também foi uma característica elencada nos depoimentos:

Ari tinha uma preocupação teórica de aprofundamento, sem se fechar em análises unilaterais [...]. (SGUISSARDI, 19 nov. 2015).

O Ari tinha preferência pelo caráter dialógico, ao sabor dos filósofos socráticos [...]. (BIACHETTI, $1{ }^{\circ}$ dez. 2015).

A ideia da universidade como um universo constituído por 'igrejinhas' (termo cunhado por ele) centradas em temáticas ou em pessoas (pesquisadores), sempre foi alvo da crítica corrosiva do Ari. (MULLER, 12 dez. 2015, grifos do autor).

Enquanto professor, o Ari dava muita autonomia, respeitava, considerava as produções, argumentações, mesmo que não 
7 Vale registrar que coincidentemente à minha entrada no doutorado, sob a orientação do Ari, em 2008, ele vivia um momento de ofertar disciplinas que tinham como objeto de estudo a obra de Álvaro Vieira Pinto, com a preocupação de aprofundar os conceitos e "divulgar o trabalho e a importância desse filósofo para a comunidade acadêmica" (BOEMER, 03/12/2015). Segundo relato de Rafael Muller (12/12/2015), o interesse pelo autor veio justamente da demanda de uma coorientação do Doutorado em Educação da UFSC: "Lembro perfeitamente que em 2006 quando entrei no doutorado e ele ficou como meu coorientador, pesquisava a temática da tecnologia em seus aspectos filosófico-antropológicos e por isso tomei contato com a leitura da obra $O$ conceito de tecnologia, de Álvaro Vieira Pinto, recém-lançada. Por se tratar de uma obra ainda desconhecida e com grande potencialidade heurística, o Ari me questionou sobre a ideia de organizar uma disciplina tendo a leitura da obra como elemento central para um debate sobre ciência, tecnologia e educação."

\footnotetext{
8 Segundo depoimento de Sguissardi (19/11/2015), dois cachorros que divertiam/ incomodavam Ari e sua vizinhança, no alto do morro da Serrinha, bairro de sua residência em Florianópolis.
}

correspondessem ainda aos construtos teóricos do Álvaro Vieira Pinto ${ }^{7}$. Era muito tranquilo, aberto para fazer críticas e recebê-las, flexível com prazos, sempre disposto, acessível para auxiliar. (BOEMER, 3 dez. 15).

Decorrente dessa abertura, a autonomia foi também traço característico em sua formação intelectual e no jeito de lidar com seus orientados, um legado de seu processo de doutoramento, sob a orientação do professor Valdemar Sguissardi (19/11/2015):

Ari foi meu primeiro orientando da UNIMEP e foi uma surpresa quando o vi no processo de seleção [...]. Era um dos estudantes mais aplicados [...]. Durante o doutorado morou em Piracicaba, o tempo todo. Não dava trabalho, tinha muita autonomia, autonomia como pesquisador. Era exigente, mas ao mesmo tempo sociável, com muitos amigos.

Legado esse que deixou aprendizados para seus orientandos, como eu e Rafael Muller (12/12/2015), do qual faço minhas suas palavras:

A principal lição que aprendi com ele no que se refere à orientação foi a possibilidade de criar autonomia. Autonomia de estudos, porém com o direcionamento dele: nunca me perguntou por que li ou por que não havia lido certos autores. Sempre me possibilitou a liberdade de leituras por vezes distantes de meu tema de pesquisa e a preocupação com os conceitos e categorias na pesquisa. Tanto a autonomia e essa última preocupação são elementos que carrego e reproduzo em minhas orientações!

\section{UMA HISTÓRIA, BREVE, DE VIDA...}

Ari Paulo Janstch nasceu no ano de 1958 e partiu prematuramente em 2010. Nesse curto período de tempo produziu sua existência, constituiu família, foi filho, irmão, companheiro e teve sua filha... estudou, escreveu, pesquisou, orientou, defendeu seus orientandos sob quaisquer condições..., fez amigos - de uma vida -, criticou acidamente incoerências, futilidades e superficialidades no/do ambiente acadêmico, ganhou desafetos..., jogou futebol, contou histórias e animou encontros entre os amigos..., negociou, comprou casa, alugou outras, emprestou seus livros..., plantou árvores, hortaliças e ervas, cuidou de criação, teve seus animais de estimação ${ }^{8}$, capinou... executou tarefas manuais e intelectuais, ambas impactantes em sua formação... passou de pequeno agricultor a professor e filósofo. Saiu da roça, mas manteve suas raízes, seja na prática - plantando, capinando, usando chapéu de palha, sendo solidário, prestativo e vivendo sua simplicidade -, 
9 Denominação dada pelo professor Valdemar Sguissardi no prefácio da edição em livro da tese de doutorado de Ari (cf. JANSTCH, 2001, p. 15). mas também nas suas preocupações filosófico-científicas, aspecto unânime nos depoimentos.

Nada melhor e mais explicitador de uma trajetória de vida do que um autodepoimento e Ari nos brinda com esse testamento escrito em sua tese de doutorado, o qual embora seja trecho longo, pela importância, uma vez que possibilita ecoar esse filósofo/educador ${ }^{9}$, segue sem cortes:

[...] ontem eu assumia com orgulho, esperança e dedicação a atividade agrícola. Ainda criança e adolescente, trabalhei muito, mesmo sem o devido instrumental para tal. Capinei, lavrei, enverguei, arranquei toco, carreguei pedra, rocei, fiz pasto e forragem, tratei, fiz lavagem, arranquei feijão e outros, cortei arroz, trigo e soja à foice de mão, tirei leite, ajudei a carnear, castrar etc., participei de muitas trilhadas, quebrei milho na roça, consertei estrada à picareta, prensei cana-de-açúcar em moenda movida a boi, fiz melado, plantei sementes a lanço ou com plantadeira manual, fiz e consertei cercas de arame farpado, fiz valetas, cavei poços, carreguei sacos, fui a pé ou à carroça de boi ao moinho e às vendas, plantei grama de potreiro... Foram muitas as tarefas - todas manuais - desempenhadas. Uma das piores foi a lida com veneno: medo, enjôo estomacal, dor de cabeça... Hoje não tolero nem o cheiro do folidol (um veneno em pó para combater as lagartas da soja). No trabalho constante e intenso, sob qualquer temperatura, mais do que realizar a esperança de um futuro melhor, prejudiquei o meu corpo, apresentando, até hoje, dentre outras, sequelas na pele e bexiga. $\mathrm{O}$ trabalho de pés descalços ou com um chinelo de dedo qualquer era uma constante; impossível era pretender um par de botas quando o dinheiro para calçar os demais irmãos era insuficiente. A miséria não se esgota nisso. Na primeira oportunidade de sair deste mundo, embora inseguro, não vacilei. Estudar para sacerdote e ser padre era bem mais atraente do que ser um agricultor. Meu desenvolvimento profissional se deu, pois, fora do espaço da atividade agrícola, quando ingressei no seminário (única oportunidade para estudar) e comecei minha carreira de intelectual - hoje atuando como professor universitário. Atualmente, com muito mais estudo, jamais voltaria espontaneamente a produzir na agricultura sem um quantum de saber científico-tecnológico bem mais avançado daquele que experimentei na primeira fase da minha vida. Minha formação geral me levou a isso. $\mathrm{E}$ vejo que os filhos dos pequenos agricultores, ao estudarem, fazem, sistematicamente, o mesmo que comecei a fazer há 25 anos. Na impossibilidade de voltarem à atividade agrícola com, dentre outros, a garantia da aplicação de um saber científico-tecnológico de grande alcance (por falta de 
incentivos adequados para a aplicação por parte de quem já domina este saber, como é o caso de muitos filhos de pequenos agricultores), simplesmente preferem ocupar postos de trabalho nas cidades, mesmo com uma baixa remuneração, ou continuar os estudos sem, no entanto, pensar em voltar à atividade agrícola. Afirma-se com isso, indiretamente e dentre outros, que a atividade agrícola, hoje, não é para amadores e que a qualificação requerida para o trabalho em tal atividade é tão ou mais complexa que a necessária ao mundo do trabalho (até hoje) tipicamente urbano. Não fosse isso não se evadiriam da terra os filhos dos pequenos agricultores e não estariam, pelo menos em tão grande número, as 'roças' (lavouras) de pequenas e médias propriedades, virando capoeira em época de recessão econômica no Brasil. Sei que tão somente o acesso ao saber altamente qualificado não 'salva a lavoura'. Constato, porém, nas muitas andanças pelo mundo dos pequenos agricultores, que o acesso ao saber, especialmente o científico-tecnológico, se constitui em uma das variáveis determinantes para quem já possui um pedaço de terra para produzir, como é o caso específico dos pequenos agricultores do sul do Brasil. Acredito que o não acesso a esse saber leva, aos poucos, os atuais 'com terra' a engrossarem, amanhã, os acampamentos dos 'sem-terra'. E se ficarmos atentos aos atuais acontecimentos, fica perfeitamente plausível a previsão de que muitos dos atuais 'sem-terra', após conquistarem e/ou reconquistarem um pedaço de terra, retornarão uma ou várias vezes para os acampamentos dos 'sem-terra'. Enfim, a posse ou a conquista da sonhada terra, hoje, por si só (isto é, aliado apenas a um trabalho instrumental e operativamente manual), não garante sequer a reprodução da pequena unidade de produção rural. (JANTSCH, 2001, p. 22-24, grifos do autor).

Além de expor a contundência de uma trajetória, nesse depoimento ficam explícitos os motivos da importância que dava para o acesso ao conhecimento "científico-tecnológico”, não só para os pequenos (ainda) agricultores, mas pela "exigência política no sentido da construção do homem e da sociedade plenas - sem barbárie alguma -" (JANSTCH, 2001, p. 25).

Para Bianchetti (em 01/12/2015), essa preocupação era muito presente nas suas aulas no curso de Pedagogia na UFSC, uma vez que percebia a dificuldade das estudantes, em sua maioria, de conseguirem sair da aparência fenomênica, passando do concreto empírico ao concreto pensado, fazendo referência aos estudos marxianos, bem como a Kosik (1976) e o conceito de pseudoconcreticidade. 
10 O ruralismo pedagógico foi um movimento educacional que ocorreu no Brasil $n$ transição do século XIX para o XX, início da República, tendo ganhado força nos anos 1930. Seus principais propagadores foram Sud Mennucci, Carneiro Leão e Manoel Bergstrom Lourenço Filho, com ideário pautado pela necessidade de fixação do homem no campo. Para saber mais consultar: Bezerra Neto (2003) e Calazans (1993), entre outros.

\section{INTERDISCIPLINARIDADE E CO- NHECIMENTO DE ALGUMAS DAS CONTRIBUIÇÕES TEÓRICO-PRÁTICAS DE ARI PAULO JANTSCH}

Produção do conhecimento e produção da existência são fenômenos compreendidos por Ari como intimamente relacionados e determinados historicamente. Dessa premissa é que se depreende o debate sobre a interdisciplinaridade realizado em sua obra, sendo uma ideia central a de que "Não se trata de destruir a interdisciplinaridade - historicamente construída e necessária - mas de lhe emprestar uma configuração efetivamente científica que, a nosso ver, seria possível por uma adequada utilização da concepção histórica da realidade" (BIANCHETTI; JANTSCH, 1995, p. 18).

Chama a atenção para que, no debate sobre a interdisciplinaridade, a "categoria da totalidade recupere toda sua força e dimensão analítica" (BIANCHETTI; JANTSCH, 1995, p. 18), juntamente com a contradição e, portanto, a história, não se reduzindo com isso à "condição meramente instrumental (MULLER; BIANCHETTI; JANTSCH, 2011, p. 192), posicionando-se contrário à "filosofia do sujeito" e seu "caráter a-histórico".

Nesse sentido efetua uma ácida crítica à interdisciplinaridade sob a ótica do capital, necessária para fazer avançar a intensificação da ciência como força produtiva, e que, em decorrência, põe em marcha a formação de um trabalhador flexível e com tarefas complexificadas, passando da primazia da força muscular para a intensificação das atividades cerebrais.

Articulado a essa discussão, porém colocando em questão o acesso ao conhecimento e a formação do pequeno (ainda) agricultor, Ari anuncia a complexidade e a interdisciplinaridade como exigências para a superação do atraso, sobretudo a consequência no Brasil do ruralismo pedagógico ${ }^{10}$. Embora haja o reconhecimento por certa contribuição originária dessa acepção, o preconceito em relação ao trabalho agrícola, pautado pela oposição campo-cidade, fundamentou as ações do Estado com políticas educativas persistentes que decretaram "a inferioridade da atividade e do homem agrícolas" (JANSTCH, 2001, p. 30).

Contrapondo-se a essa tendência Ari tem como pressuposto a afirmação de que existem as condições objetivas suficientes para a realização do Homem Universal, isto é, dos indivíduos humanos como seres plenos, com formação omnilateral e "cidadania universal", "usufruinte indiscriminado das conquistas civilizatórias, dentre elas, a ciência-tecnologia própria da atual revolução científico-tecnológica". Dessa forma, defende a tese de que o pequeno (ainda) agricultor precisa de "uma educação geral e científico-tecnológica igual (ou possivelmente superior) aos demais trabalhadores, elevando-o inclusive à condição de trabalhador intelectual (pesquisador)" (JANSTCH, 20012, p. 28-29). 
A interdisciplinaridade assume um significado fundamental, apreendida a partir do que Etges (2004, p. 8384) propõe:

A interdisciplinaridade não poderá jamais consistir em reduzir as ciências a um denominador comum, que sempre acaba destruindo a especificidade de cada uma, de um lado, e dissolve cada vez mais os conteúdos vivos em formalizações vazias, que nada explicam, podendo, pelo contrário, transformar-se em estratégias de exclusão e de domínio absoluto. Pelo contrário, deverá ser um mediador que possibilita a compreensão da ciência, além de formas de cooperação a um nível bem mais crítico e criativo entre os cientistas.

Nesse ponto vale destacar que o acesso ao conhecimento, com a ênfase no agricultor, e o esvaziamento da formação, colocado na perspectiva da interdisciplinaridade sob o capital, é uma preocupação constante nas obras de Ari, algo que também se relaciona com sua história de vida.

Seu último texto publicado demarca com força a crítica à mercadorização do ensino superior, com o enfoque no fato de que a universidade demandada pelo mercado não produz conhecimento. Tal texto (JANSTCH, 2010) é considerado por Sguissardi (em 19/11/2015), Bianchetti (em 01/12/2015) e Guimarães (em 03/12/2015) como a obra-prima, uma espécie de coroamento, síntese de sua trajetória. Fica a questão: pode um trabalhador-pesquisador determinado pelo mercado, produzir com a devida profundidade conceitual no sentido da emancipação humana?

O enfrentamento ao capital mediante um rigor filosófico-científico e uma razão radical já aparece em uma de suas primeiras publicações, em 1993, no livro "O conhecimento popular”, escrito juntamente com Sergio Schaefer. Nilton Bueno Fischer, seu orientador no mestrado em educação na UFRGS, na "Apresentação" do referido livro, afirma como um dos aspectos interessantes o fato de que "os autores deixam claro que não realizaram o trabalho independente de suas convicções políticas e de suas concepções sobre as necessárias mudanças que devem ocorrer na sociedade" (FISCHER, 1993, s/p).

Desde seu início como professor-pesquisador, tais convicções orientaram e balizaram a produção intelectual, com a busca constante por uma coerência, evidenciada pela não aceitação em ser bolsista produtividade do Conselho Nacional de Desenvolvimento Cienífico e Tecnológico - CNPQ (cf. Guimarães em 03/12/2015), sem contudo abrir mão de contribuir com a Pós-Graduação em âmbito nacional. Sobre esse último item destaca-se que Ari teve várias ações, como por exemplo, a Associação Nacional de Pós-Graduação e Pesquisa em Educação - ANPED - como a participação ativa nos primórdios da criação, e posterior coordenação, do Grupo de Trabalho 17 (BIANCHETTI, 
${ }^{11}$ Termos utilizados pelo Ari no último capítulo de sua tese (JANTSCH, 2001, p. 223).
2011, p. 9), ou ainda assumindo a coordenação de experiências interinstitucionais, sem, contudo, não deixar de analisá-las criticamente, como em Jantsch (2013).

\section{INTERCESSÕES COM A EDUCAÇÃO DO CAMPO, CONCLUINDO "PROVÁVEL E PROVISORIAMENTE"11}

Como falo de um lugar - sou professora da Licenciatura em Educação do Campo na UFSC, e, enquanto fui orientada pelo Ari, busquei fazer essa interlocução com ele - nesse último item destaco eixos de sua produção, os quais considero essenciais para o debate teórico-prático da Educação do Campo. Considerando o enfoque escolhido, a interlocução dessas reflexões foi feita basicamente com sua tese de doutorado, sem descartar as contribuições dos demais textos.

A especificidade diante da individuação do Homem Universal, no bojo do entendimento da superação do pequeno (ainda) agricultor para o produtor de alimentos e sua devida formação omnilateral, possibilitando educação geral e de caráter científico-tecnológico é uma compreensão que remete aos pressupostos marxianos da passagem do reino da necessidade ao reino da liberdade, conforme expõe Manacorda (2000).

A noção de produtor de alimentos, não mais vinculado a um determinado espaço ou setor de atividades, remete ao trecho de A ideologia alemã, de Marx e Engels (1999, p. 47):

Com efeito, desde o instante em que o trabalho começa a ser distribuído, cada um dispõe de uma esfera de atividade exclusiva e determinada, que lhe é imposta e da qual não pode sair; o homem é caçador, pescador, pastor ou crítico e aí deve permanecer se não quiser perder seus meios de vida ao passo que na sociedade comunista, onde cada um não tem uma esfera de atividade exclusiva, mas pode aperfeiçoar-se no ramo que lhe apraz, a sociedade regula a produção geral, dando-me assim a possibilidade de hoje fazer tal coisa, amanhã outra, caçar pela manhã, pescar à tarde, criar animais ao anoitecer, criticar após o jantar, segundo o meu desejo, sem jamais tornar-me caçador, pescador, pastor ou crítico.

Os debates e produções da Educação do Campo, ao afirmarem uma educação que tenha vínculo com a realidade do campo, que seja "no e do" campo, se tiverem como horizonte a superação da ordem do capital, precisam incorporar e/ou revisitar essa importante passagem dos autores acima citados, bem como a sua consequente noção do Homem Universal abordado por Ari. Caso contrário, corre-se o risco de um retrocesso aos pressupostos da educação rural e, portanto, da negação da própria Educação do 
${ }^{12}$ O Ministério da Educação, pela Secretaria de Alfabetização Continuada, Diversidade e Inclusão publicou três Editais Públicos, em 2008, 2009 e 2012, voltados às instituições públicas de ensino superior, como ação do Programa de Apoio à Formação Superior em Licenciatura em Educação do Campo, voltado para a formação de educadores para os anos fanais do Ensino Fundamental e o Ensino Médio nas escolas do campo. Para verificar mais detalhes consultar a página oficial do Ministério da Educação: http://portal. mec.gov.br/tv-mec.
${ }^{13} \mathrm{O}$ grupo que organizou a homenagem foi composto pelas seguintes pessoas: da UDESC, professora Elisa Maria Quartiero, e da UFSC, professor Lucídio Bianchetti, técnico-administrativo Mauro J. Tonon, e eu, Natacha Eugênia Janata, que na ocasião havia perdido meu orientador no Programa de Pós-Graduação em Educação.
Campo como originária das contradições entre as lutas dos movimentos sociais do campo e o Estado no interior das relações sociais de produção capitalistas.

A interdisciplinaridade, no bojo da discussão da formação para a docência multidisciplinar por área de conhecimento nas Licenciaturas em Educação do Campo, previstas nos Editais Públicos, lançados pelo Ministério de Educação desde $2008^{12}$, a partir das leituras referenciadas por Ari, precisa ser ampla e profundamente estudada, debatida, confrontada. Isso porque na contradição entre as lutas e conquistas dos movimentos sociais e a implementação de políticas sob a ordem do capital, é imprescindível a clareza filosófico-científica de que rumos se assumem ao invocar a tal interdisciplinaridade. Para isso, Ari aponta veementemente o estudo epistemológico como essencial, compreendendo, com demais autores, que: "a riqueza, seja na pesquisa, seja na socialização do conhecimento, não está na dissolução das fronteiras, mas na contribuição - mesmo que muitas vezes tensionante - e na comunicação entre e intra as várias disciplinas, ciências e áreas" (MULLER; BIANCHETTI, JANTSCH, 2011, p. 193).

Ainda que possa haver pontos de discordâncias algo que comumente era a porta de entrada para calorosos debate, e nessa perspectiva, bastante saudável para a minha produção acadêmica -, a postura/contribuição do Ari é extremamente atual e relevante para a Educação do Campo. Ele fez a crítica à educação rural e ao ruralismo pedagógico, mas não desconsiderou suas contribuições para a educação do pequeno (ainda) agricultor, apontando, por outro lado, a necessária superação dela, assumindo, como já citado a complexidade e a interdisciplinaridade como exigência dessa formação.

Assim como Ari fez com o pensamento e a produção de Álvaro Vieira Pinto, justamente nos seus últimos anos, cabe aos estudiosos da Educação do Campo apropriarem-se criticamente da sua obra (contundente e radical) a fim de contribuir com os rumos da Educação do Campo do sul e de todo o país, e por fim, para ser fiel ao pensamento dele, à individuação do Homem Universal dos pequenos (ainda) agricultores, posto que "a atividade agrícola, hoje, não é para amadores e que a qualificação requerida para o trabalho em tal atividade é tão ou mais complexa que a necessária ao mundo do trabalho (até hoje) tipicamente urbano" (JANTSCH, 2001, p. 23-24).

\section{BOX: BREVE BIOGRAFIA DE ARI PAULO JANSTCH}

Como complementação ao exposto, segue trecho de uma homenagem feita ao Ari no dia 30/04/2010, na Universidade Federal de Santa Catarina, coordenada pelo professor Lucídio Bianchetti ${ }^{13}$, tendo a minha participação: 
- Filho do Sr. Alberto I. Jantsch e Maria Leonida Jantsch, Ari Paulo Jantsch nasceu em 02/04/1958, em Porto Alegre. É o segundo filho de uma família de 11 irmãos. Foi registrado no município de Estrela, RS.

- Foi seminarista pela ordem dos Oblatos de São Francisco de Sales (em Viamão, RS), de março de 1972 a fevereiro de 1983, tendo feito noviciado e três anos de votos temporários. - Cursou Filosofia pela (então) FAFIMC (Faculdade de Filosofia Nossa Senhora Imaculada Conceição), em Viamão, no período de 1978-1981.

- Foi diretor da Escola Municipal Santa Maria, em Viamão (1982-1983);

- Cursou Mestrado em Educação na UFRGS, sob a orientação do professor Nilton Bueno Fischer, no período de 1983 a 1986. Sua dissertação tem o título: Planejamento participativo na educação - do operacional à filosofia da educação: estudo de caso da Escola de $1 .^{\circ}$ e 2. ${ }^{\circ}$ Graus 'Educar-se'.

- Após o mestrado fez também uma especialização em Educação Popular, de 1987 a 1988, na Universidade de Santa Cruz do Sul (UNISC).

- Começou a lecionar no Ensino Superior em dezembro de 1983 na FISC (hoje UNISC: Santa Cruz do Sul, RS), onde foi chefe do Departamento de Educação, Coordenador dos Cursos de Pós-Graduação e cofundador da Revista Reflexão e Ação.

- Também foi professor da Escola de $10^{\circ}$ e $2 .^{\circ}$ Graus 'Educar-se' (Escola de Aplicação da FISC, hoje UNISC) e professor (último nível) do Estado do RS (no Polivalente de Vera Cruz e em Monte Alverne - Santa Cruz do Sul).

- Em Santa Cruz do Sul, RS, casou-se com Dercy Akele no dia 04/05/1987. Desse casamento nasceu sua filha, Ana Cláudia Akele Jantsch, em 02/03/88.

- Em agosto de 1991 saiu da UNISC para ingressar na Universidade Federal de Santa Catarina - UFSC, inserindo-se gradativamente nas atividades de ensino na graduação e na pós-graduação no curso de Enfermagem e na Educação, na orientação de mestrandos e doutorandos, envolvendo-se também nas atividades de pesquisa e extensão.

- Coordenou o Mestrado Interinstitucional a distância - Plano Sul de Pós-graduação PPGE/UNOESC/UNOCHAPECÓ, convênio CAPES/FAPESC/PPGE/UFSC.

- Coordenou e vinha colaborando ativamente com o NUP (Núcleo de Publicações).

- Realizou Curso de Doutorado em Educação na UNIMEP, em Piracicaba, SP, sob a orientação do professor Valdemar Sguissardi, tendo concluído a tese em 15/08/97, cujo título é: Pequeno (ainda) agricultor e racionalidade educativa.

- Realizou seu pós-doutorado, em parceria com o prof. Nilton Bueno Fischer, no Programa de 
Pós-Graduação em Educação da Universidade Federal do Rio Grande do Sul, no período de dezembro de 2001 a novembro de 2002.

- Sem contar as coorientações, levou 14 mestrandos à apresentação pública e 7 doutorandos à defesa.

- Sua vida acadêmica também conta com apresentação de trabalhos científicos em congressos e similares, participação em cursos de extensão e eventos universitários, publicações e outras atividades.

- Além da publicação de muitos artigos e trabalhos em ANAIS de Congressos, foi organizador e autor de 5 livros.

- Como pesquisador esteve envolvido na coordenação de projetos de pesquisa, que focalizavam principalmente os temas: epistemologia, conceitos e categorias, trabalho e educação, filosofia da educação, pequeno agricultor e MST, educação/formação científico-tecnológica.

- No PPGE/CED/UFSC integrava as linhas de pesquisa 'Trabalho e Educação' e 'Filosofia da Educação'.

- Era membro do corpo editorial de diversas revistas.

- Em 1993, juntamente com Norberto Etges e Lucídio Bianchetti, elaborou e foi signatário do documento que criou o Grupo de Estudos (GE) em 'Filosofia da Educação' da ANPEd. Dois anos após, o Grupo de Estudos foi transformado em Grupo de Trabalho (GT) de 'Filosofia da Educação', sendo o GT de n. 17 da ANPEd. Deste GT, o Ari foi Coordenador por dois anos.

- Em 2010, coordenava o curso de doutorado Interinstitucional - DINTER, convênio CAPES/FAPESC/UFSC/PPGE/PPGECT/IFSC. (BIACHETTI et al., 2010).

\section{REFERÊNCIAS}

BEZZERA NETO, L. Avanços e retrocessos da educação rural no Brasil. Tese (Doutorado em Educação) Universidade Estadual de Campinas, Campinas, 2003.

CALAZANS, Maria Julienta Costa. Para compreender a educação do estado no meio rural: traços de uma trajetória. In: THERRIEN, Jacques; DAMASCENO, Maria Nobre (Coord.). Educação e escola no campo, Campinas: Papirus, 1993

BIANCHETTI, Lucídio et al. Homenagem prestada ao Ari. Centro de Ciências da Educação, UFSC, Florianópolis, 2010. Texto não publicado.

ETGES, Norberto. Ciência, interdisciplinaridade e educação. In: JANTSCH, Ari Paulo, BIACNHETTI, Lucídio. (Orgs.). Interdisciplinaridade: para além da filosofia do sujeito. 9. ed. Petrópolis: Vozes, 2011. 
FISCHER, Nilton B. Apresentação. In: SCHAEFER, Sérgio. JANSTCH, Ari P. O conhecimento popular. Santa Cruz do Sul: Editora da UNISC, 1993.

JANTSCH, Ari Paulo, BIACNHETTI, Lucídio. (Orgs.). Interdisciplinaridade: para além da filosofia do sujeito. 9. ed. Petrópolis: Vozes, 2011.

JANTSCH, Ari Paulo. Mercadorização, formação, universidade pública e pesquisa crítico- emancipatória: em tempos de realização plena do conceito de capital. In: OLIVEIRA, João Ferreira; CATANI, Afrânio Mendes; SILVA JUNIOR, João dos Reis (Org.). Educação superior no Brasil: tempos de internacionalização. São Paulo: Xamã, 2010. p. 35-78.

.Pequeno (ainda) agricultor e racionalidade educativa. Florianópolis: NUP, 2001.

; BIACNHETTI, Lucídio. (Orgs.). Interdisciplinaridade: para além da filosofia do sujeito. Petrópolis: Vozes, 1995.

KOSIK, Karel. Dialética do concreto. Paz e Terra, 1976.

MANACORDA, Mario A. Marx e a pedagogia moderna. São Paulo: Cortez, 2000.

MARX, Karl; ENGELS, Friedrich. A ideologia alemã. 11. ed. São Paulo: Hucitec, 1999.

MULLER, Rafael R.; BIANCHETTI, Lucídio; JANSTCH, Ari P. Interdisciplinaridade, pesquisa e formação de trabalhadores: as interações entre o mundo do trabalho e da educação. In: JANTSCH, Ari Paulo, BIACNHETTI, Lucídio. (Orgs.). Interdisciplinaridade: para além da filosofia do sujeito. 9. ed. Petrópolis: Vozes, 2011.

SCHAEFER, Sérgio. JANSTCH, Ari P. O conhecimento popular. Santa Cruz do Sul: Editora da UNISC, 1993. 